\author{
Military Technical College \\ Kobry El-Kobbah, \\ Cairo, Egypt
}

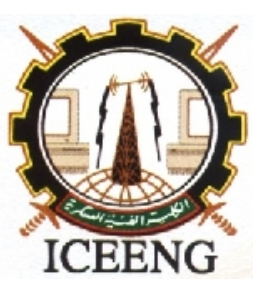

\author{
$8^{\text {th }}$ International Conference \\ on Electrical Engineering \\ ICEENG 2012
}

\title{
Novel real-time stability assessment algorithm based on synchro-phasors measurement and parallel algorithms for multi-machine networks
}

\author{
By \\ Mohamed A. Ali * Wael R. Anis ** Wagdy M. Mansour *** Fahmy M. Bendary***
}

\section{Abstract:}

The paper presents an approach to design power system transient stability assessment using direct methods for a multi-machine network based on multiple synchronized phasors, measured from Phasor Measurement Units (PMUs) and generator parameters. The generator rotor angle was derived from phasor measurements of voltage and current, and generator parameters using direct real-time algorithm. The multi-machine system was reduced to groups denoted Single Machine to Equivalent Bus (SMEB) models and another groups denoted Load Equivalent Bus (LEB) using Parallel Algorithms (PAs). The use of these PAs eliminates the SPMUs at each bus in the system, and it is required number of SPMUs only equals the number of generator buses. So that, the Equal Area Criterion in both rotor angle domain and time domain can be applicable for the SMEBs groups to assess the system stability in real-time. A three phase fault was simulated at test system comprises 2-machine, 8-bus network for validating the novel algorithm.

\section{Keywords:}

Stability Assessment, Multi-machine, Parallel Algorithms, Real-time, Synchro-Phasors Measurement Units.

* Lecturer assistant, faculty of engineering shoubra, Benha university

** Assisstant professor, faculty of engineering, Zagazig university

*** Professor, faculty of engineering shoubra, Benha university 


\section{Introduction:}

Synchro-phasor measurements of synchronized voltage and current are used by utilities to control and stabilize the power network. The dependence of the machine on the position of the rotor makes it difficult for the application of phasor measurements for stability control methods. Under transient conditions, it is not easy to find solutions to obtain machine voltages, currents and flux linkages when expressed in phase quantities. The time varying coefficients need to be stabilized to obtain stationary mechanical coefficients [1,2]. Phasor measurement units equipped with Global Positioning System (GPS) receivers and a time-stamp device are placed at power plants to obtain power plant variables. The gathered data is then transmitted to a central location where the data can be compared, analyzed and processed .With some local processing power they can be used to determine the generator angles, speeds, accelerations and powers from terminal voltages and currents $[1,3]$. Prior knowledge of the system is necessary since the network topology changes would influence proper machine identification. Lack of direct measurement of the plant auxiliaries may result in phasor measurements not providing a real picture of rotor angles. Previously two multi-layered feed-forward artificial neural networks have been used to estimate rotor angles and speed from phasor measurements. This solution did not consider the lack of direct measurements as a source of uncertainties. Selection of input variables was also not considered [4, 5]. The generator measurable outputs with its electrical parameters have been used to estimate the state variables. The results did not use the availability of the field voltage $\mathrm{E}_{\mathrm{fd}}$, which provides additional insight into the internal machine flux linkages [2].

This paper presents an algorithm to detect the multi-machine networks stability in realtime via the SPMUs and PAs which reduces the original multi-machine network to groups denoted by Single Machine to Equivalent Bus (SMEB) models and another groups denoted by Load Equivalent Bus (LEB) models using Parallel Algorithms (PAs) [1].

The generators rotor angle can be determined by real-time Rotor Angle Detection (RAD) algorithm. The RAD algorithm can detect the generator rotor angle by SPMUs measurements (installed at high tension side) and generator parameters. The network stability can be assessed by the comulative energy produced by each machine during the first swing. If the first swing energy is negative the system will be stable but, if it is positive the system will be unstable. The comprehensive description for each part of the novel algortihm will be illustrated in the following sections. 


\section{Parallel Algorithms (PAs)}

The first part of the algorithm is converting the multi-machine system to several groups of single machine/load buses. The multi-machine power system can be factiously devided to equivalent groups of SMEBs and LEBs depending of the existing number of generator buses and load buses. The equivalents can be obtained using special procedure [1] to determine the equivalent parameters for each SMEB and LEB model which are equivalent admittance magnitude $\left(\mathrm{Y}_{\mathrm{eq}}\right)$, and angle $\left(\rho_{\mathrm{eq}}\right)$. Also, equivalent bus voltage magnitude and angle respectively Veq, and aeq. The following equations were concluded [1] and listed below.

$$
\begin{aligned}
& \mathrm{Y}_{\text {eqi }}=\sqrt{\mathrm{A}_{\mathrm{i}}^{2}+\mathrm{B}_{\mathrm{i}}^{2}} \\
& \rho_{\text {eqi }}=\tan ^{-1}\left(\frac{\mathrm{A}_{\mathrm{i}}}{\mathrm{B}_{\mathrm{i}}}\right) \\
& \mathrm{V}_{\text {eqi }}=\frac{\sqrt{\mathrm{C}_{\mathrm{i}}^{2}+\mathrm{D}_{\mathrm{i}}^{2}}}{\mathrm{Y}_{\text {eqi }}} \\
& \alpha_{\text {eqi }}=\tan ^{-1}\left(\frac{\mathrm{C}_{\mathrm{i}}}{\mathrm{D}_{\mathrm{i}}}\right)-\rho_{\text {eqi }}
\end{aligned}
$$

Where,

$$
\begin{aligned}
& \mathrm{A}_{\mathrm{i}}=\mathrm{Y}_{\mathrm{ii}} \sin \rho_{\mathrm{ii}} \\
& \mathrm{B}_{\mathrm{i}}=\mathrm{Y}_{\mathrm{ii}} \cos \rho_{\mathrm{ii}} \\
& \mathrm{C}_{\mathrm{i}}=\underset{\substack{\mathrm{j}=1 \\
\mathrm{j}, \mathrm{i}}}{+\mathrm{n}} \mathrm{J}_{\mathrm{j}} \mathrm{Y}_{\mathrm{ij}} \sin \left(\rho_{\mathrm{ij}}+\alpha_{\mathrm{j}}\right) \\
& D_{i}=\underset{\substack{j=1 \\
j 0, i}}{+{ }_{j}} V_{j} Y_{i j} \cos \left(\rho_{i j}+\alpha_{j}\right)
\end{aligned}
$$

\section{Online Rotor Angle Detection Algorithm}

The next step in the algorithm is detecting the generator rotor angle using RAD algorithm. Generators in real-time is considered an important issue. So that, the need for real time measurements is the solution key via the implementation of the Phasors Measurement Units (SPMUs). But, the issue is to find how to detect the stability of the generators using these PMUs in power system networks. Thus, in this paper the 
implementation of PMUs to detect the rotor angle stability via the proposed real-time RAD algorithm will be presented. The algorithm uses the real-time measurements via PMUs then detects the generator rotor angle instant by instant and makes rotor angle monitoring, supervision, and control. The algorithm implementing the measurements of currents and voltages via the installed generator PMU at the high tension side of the step up transformer as shown in figure.1.

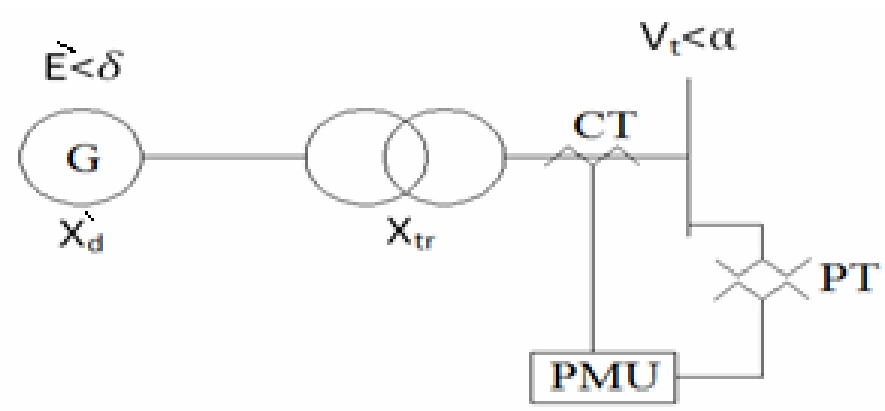

Figure (1): Sample generator/transformer set with PMU installed at H.V side

To derive direct equation to be implemented to detect the generator rotor angle in realtime, it is important to be based on real-time measurements and fixed generator data sheet parameters. The generator rotor angle equation can be found by calculating the electrical active and reactive power delivered to the network from the generator and

also, terminal voltage angle $(-)$ which can be directly measured instantly via the PMU

as shown in figure.1. Also, can be calculated according to equation (9), and equation (10) respectively for the classical model.

$\mathrm{P}_{\mathrm{e}}=\frac{\dot{\mathrm{E}} \mathrm{V}_{\mathrm{t}}}{\hat{\mathrm{X}}_{\mathrm{d}}+\mathrm{X}_{\mathrm{tr}}} \sin (\delta-\alpha)$

$\mathrm{Q}_{\mathrm{e}}=\frac{\hat{\mathrm{E}}_{\mathrm{t}}}{\hat{\mathrm{X}}_{\mathrm{d}}+\mathrm{X}_{\mathrm{tr}}} \cos (\delta-\alpha)+\frac{\grave{\mathrm{E}}^{2}}{\hat{\mathrm{X}}_{\mathrm{d}}}$

According to equation (9), and equation (10) the generator rotor angle can be deduced as follows; 


$$
\delta=\alpha+\tan ^{-1} \frac{\mathbf{P}_{\mathrm{e}}}{\mathbf{Q}_{\mathrm{e}}-\frac{\dot{\mathrm{E}}^{2}}{\overline{\mathrm{X}}_{\mathrm{d}}}}
$$

So that, the generator rotor angle can be detected using equation (11) which depends on real-time measured parameters which are $\mathrm{P}_{\mathrm{e}}, \mathrm{Q}_{\mathrm{e}}, \alpha$, and $\hat{E}$. Also, generator data sheet parameter which is $\hat{X}_{\mathrm{d}}$. All previous steps are just for monitoring and control but for tripping decision it depends on the energy equilibrium theorem of the first swing for each machine.

Also, for the detailed current model the following equation can be used for determining the machine rotor angle as follows,

$\delta=\alpha-\tan ^{-1} \frac{\mathbf{V}_{\mathrm{DA}}}{\mathbf{V}_{\mathrm{QA}}}$

Where,

$$
\begin{aligned}
& V_{D A}=V_{e q d}+\left(r_{d}+R_{e q}\right) i_{d}+\frac{\omega}{\omega_{o}}\left(X_{h q} i_{D q}-\left(\mathrm{X}_{\mathrm{q}}+X_{e q}\right) i_{q}\right) \\
& \mathrm{V}_{\mathrm{QA}}=V_{e q q}+\left(r_{q}+R_{e q}\right) i_{q}-\frac{\omega}{\omega_{o}}\left(X_{h d} i_{f}+X_{h d} i_{D d}-\left(\mathrm{X}_{\mathrm{d}}+X_{e q}\right) i_{d}\right)
\end{aligned}
$$

Where, $\mathrm{V}_{\mathrm{DA}}$ and $\mathrm{V}_{\mathrm{QA}}$ are equivalent bus voltage alonge $\mathrm{D}$-axis and Q-axis respectivily. According to equation (12) $=$ can be determined directly from phasor PMU measurements and machine nameplate parameters. But, for the sake of simplicity, the damper currents could be neglected. Whereas, for more accuracy, the damper currents can be determined via the real-time PAs as descriped in the paper.

It is important to consider that the algorithm accuracy depends on the resolution step (number of samples per cycle) of the PMUs. Thus, the increase of number of samples per cycle, the increase of algorithm accuracy. 20 samples per cycle (for $50 \mathrm{~Hz}$ systems) i.e. measuring via PMUs every $1 \mathrm{~ms}$ is sufficient for the algorithm for very satisfactory accuracy.

\section{Stability Assessment of Multi-Machine Networks}

Employing the above two algorithms PAs, and real-time RAD algorithm in multi-

machine network. The stability assessment can be detected via tracing the P- instant- 
by-instant to determine the first swing energy. If negative energy is detected the system will be stable, but if positive energy detected the system will be unstable and loss of synchronism will occurred. So, remedial actions have to be applied to trip the unstable machine. Chart depicts the stability assessment algorithm of multi-machine networks is presented in figure 2 .

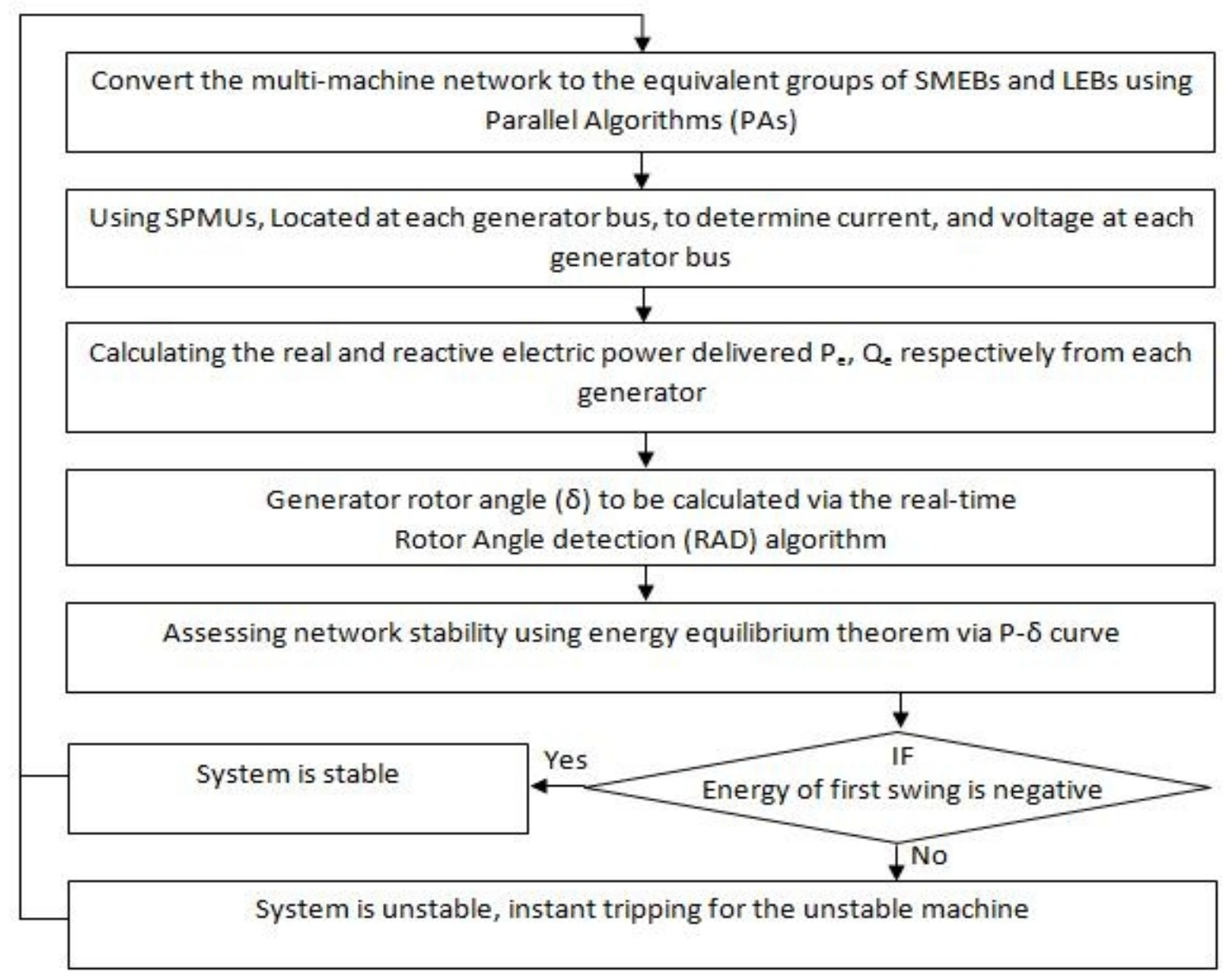

Figure (2): flow chart of the novel stability algorithm

\section{Modeling And Simulation}

The employed power system is simulated using detailed model for synchronous machine representation. The power system model is simulated using MATLAB (version 7.0) programs created by the authors. Due to the unavilability of SPMUs, off-line simulation is performed by the PAs to develop an output results are considered as the real measurements taked by the SPMUs. 


\section{Simulation Results}

The test system comprises 2-machine, 8-bus network shown in figure 3. So, it can be reduced to two SMEBs by the PAs as mentioned in section II. SMEBs are shown in figure 4, also LEBs are shown in figure 5. The resulting SMEBs are used via the realtime RAD algorithm. The volatges and currents measurements for load buses can be calculated directly from the resulting LEBs from the PAs. The system is simulated under several fault duration. The first swing enegry for each machine is presented in table 1.

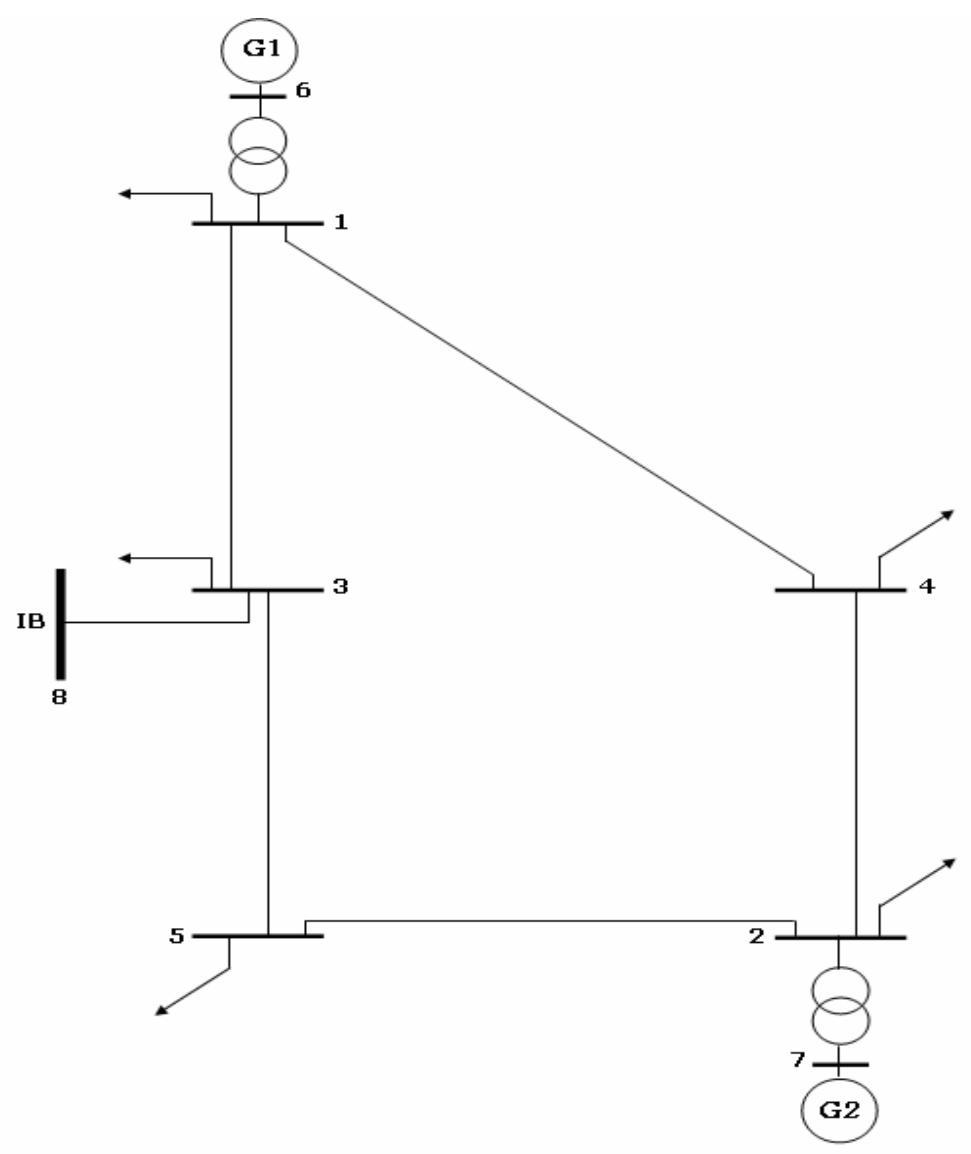

Figure (3): The original network of the test system

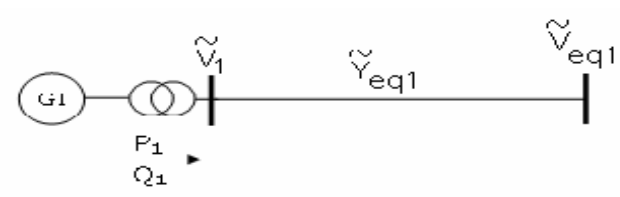




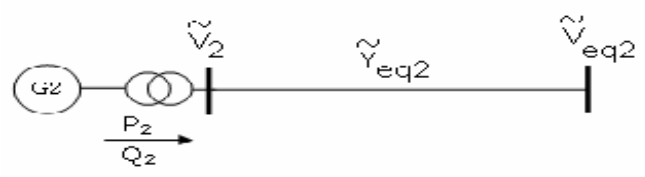

Figure (4): The transformed SMEBs
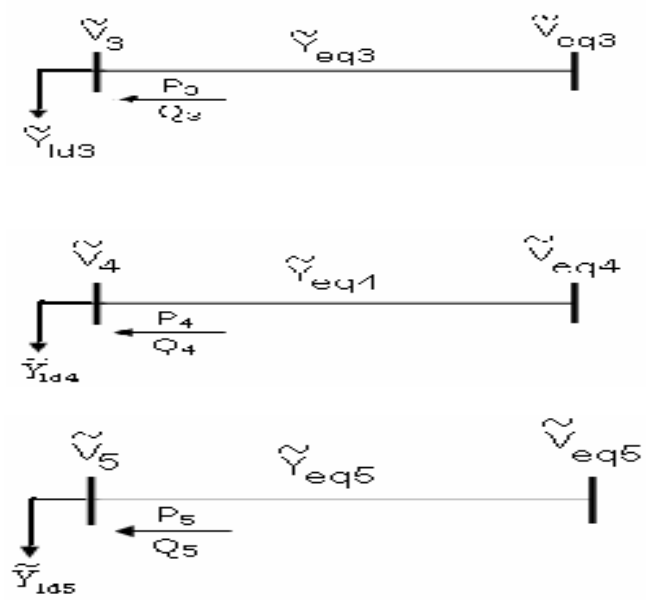

Figure (5): The transformed LEBs

Table (1): First swing area for both machines under several fault durations

\begin{tabular}{|c|c|c|c|}
\hline $\begin{array}{c}\text { Fault } \\
\text { Duration }\end{array}$ & $\begin{array}{c}\text { Area of } \\
\text { M/C No. 1 }\end{array}$ & $\begin{array}{c}\text { Area of } \\
\text { M/C No.2 }\end{array}$ & Status \\
\hline $100 \mathrm{~ms}$ & -0.00067457 & -0.0010139 & Stable \\
\hline $150 \mathrm{~ms}$ & -0.0027 & -0.00055126 & Stable \\
\hline $200 \mathrm{~ms}$ & -0.0014 & -0.0017148 & Stable \\
\hline $250 \mathrm{~ms}$ & -0.00058738 & -0.00088106 & Stable \\
\hline $300 \mathrm{~ms}$ & -0.0036886 & -0.001527 & Stable \\
\hline $400 \mathrm{~ms}$ & 5.5396 & 2.2319 & Unstable \\
\hline
\end{tabular}

Figure.6 presents the viration in electric power delivered from machine No.1versus power angle variation for $200 \mathrm{~ms}$ fault. But, it is found that it is not clear for the required information about first swing energy. Thus, a 3-D graph $(\mathrm{P}-\delta-\mathrm{t})$ is develeped in figure.7 showing clearly the first swing energy. Also, for more clearence, zoomed shot for the first swing is presented in figure.8. Figure (9:11) is similar to what desciped for figure (6:8) but for machine No.2. The algorithm develop an alarm message indicates system is stable. The stable alarm message is presented in figure. 12 . 


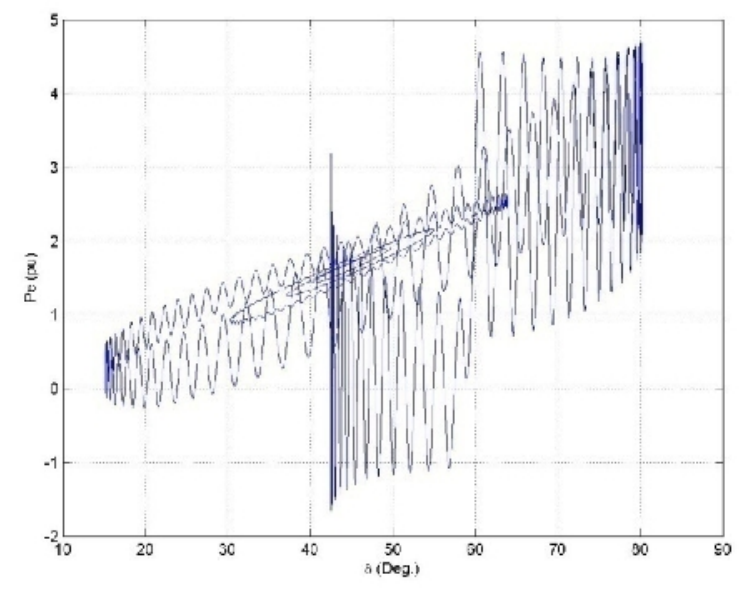

Figure (6): Machine No.1 P-ô curve for 200ms 3-phase fault

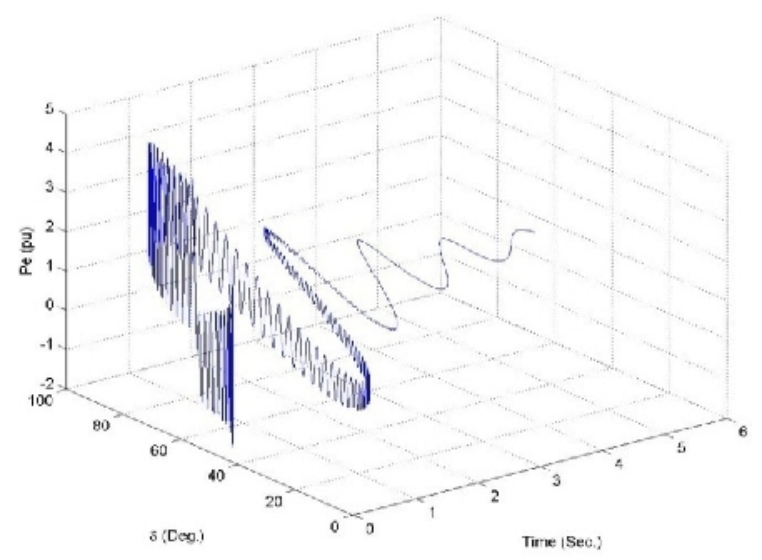

Figure (7): Machine No.1 P-ô-t curve for 200ms 3-phase fault 


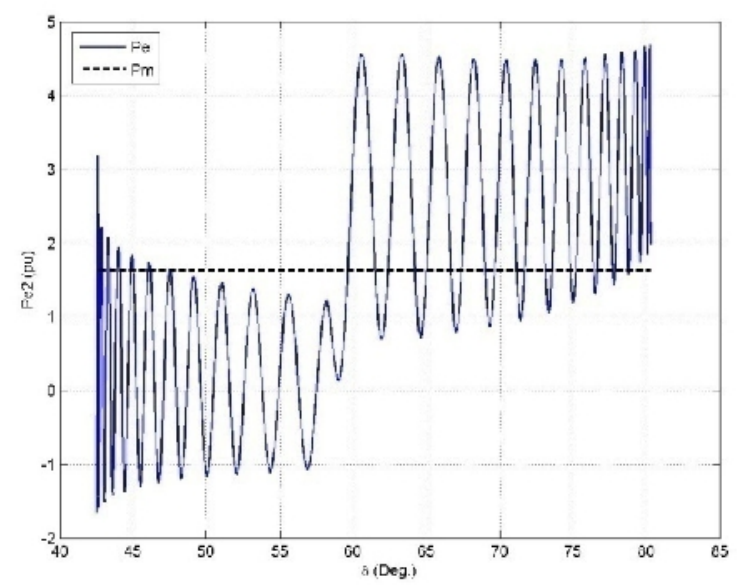

Figure (8): First swing of machine No.1 arround $P_{m}$ for 200ms 3-phase fault

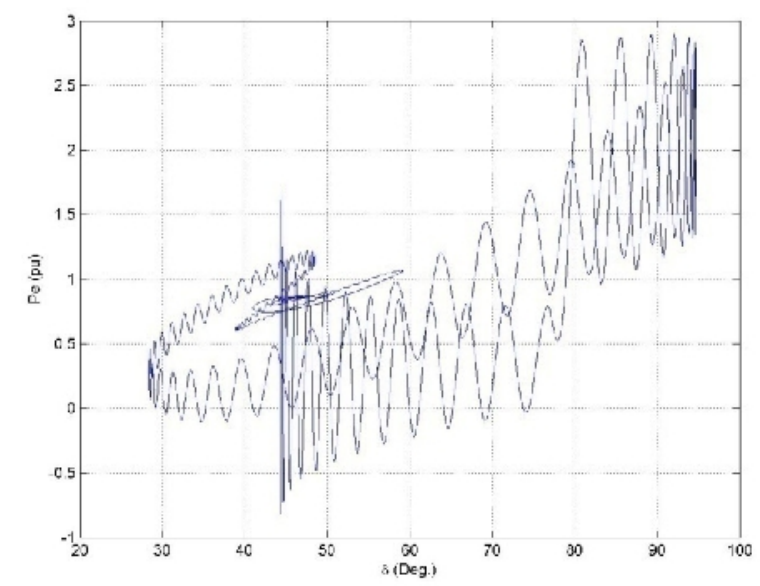

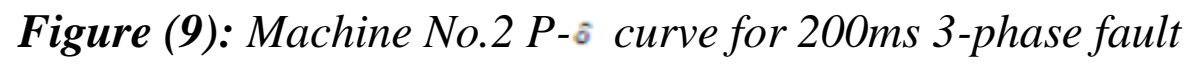

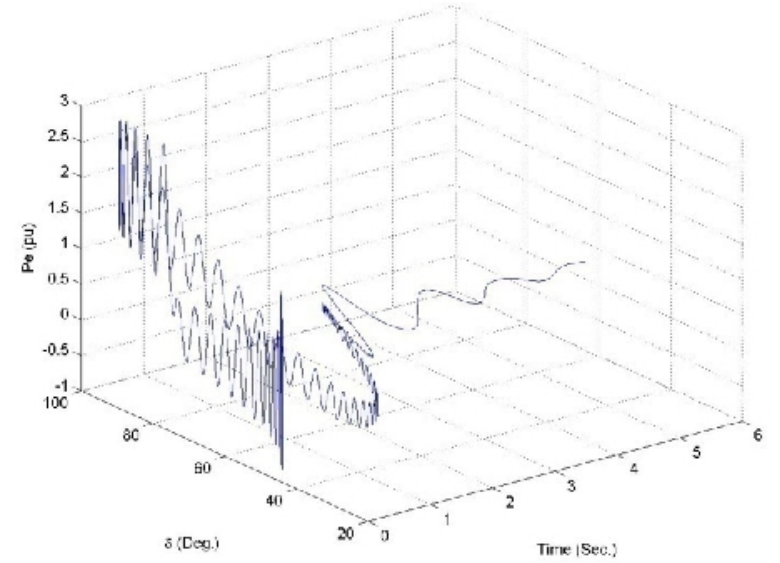

Figure (10): Machine No.2 P-ô-t curve for 200ms 3-phase fault 


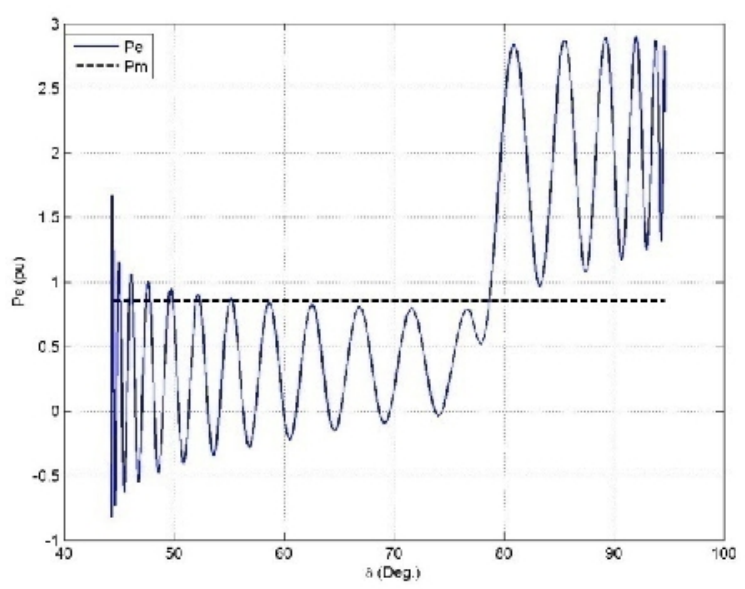

Figure (11): First swing of machine No.2 arround $P_{m}$ for 200ms 3-phase fault

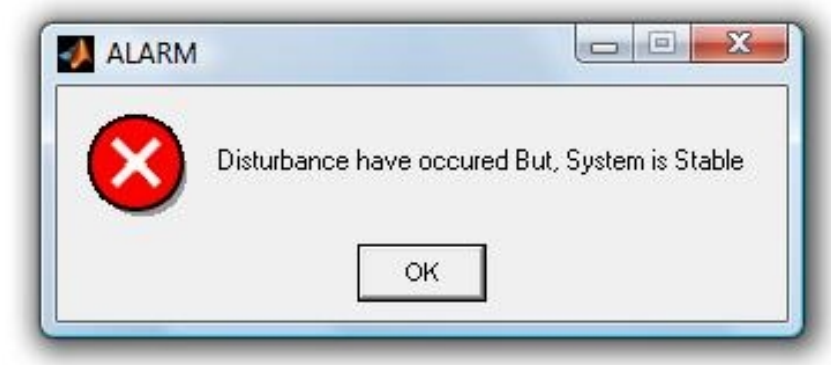

Figure (12): Alarm message for stable case

Figure (13:14) show the power variations due to $400 \mathrm{~ms}$ fault, also, the unstable alarm message prseneted by the algorithm is shown in figure. 15 .

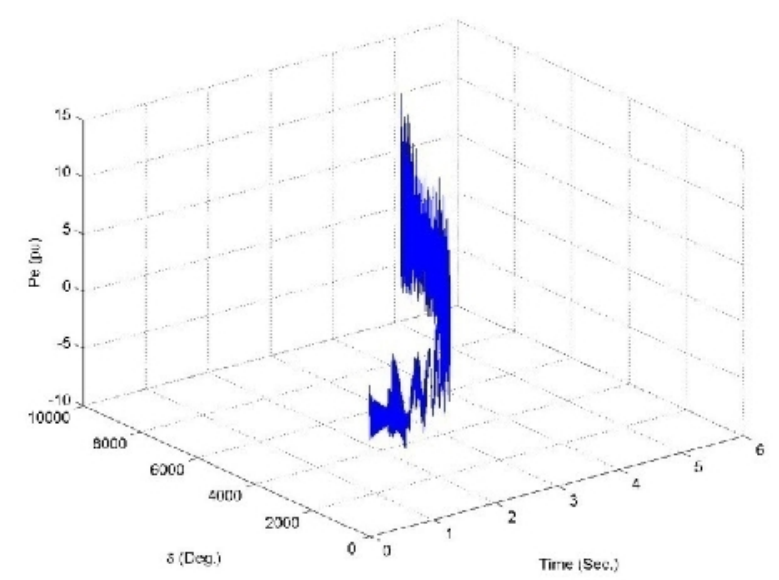

Figure (13): Machine No.1 P-ô-t curve for 400ms 3-phase fault 


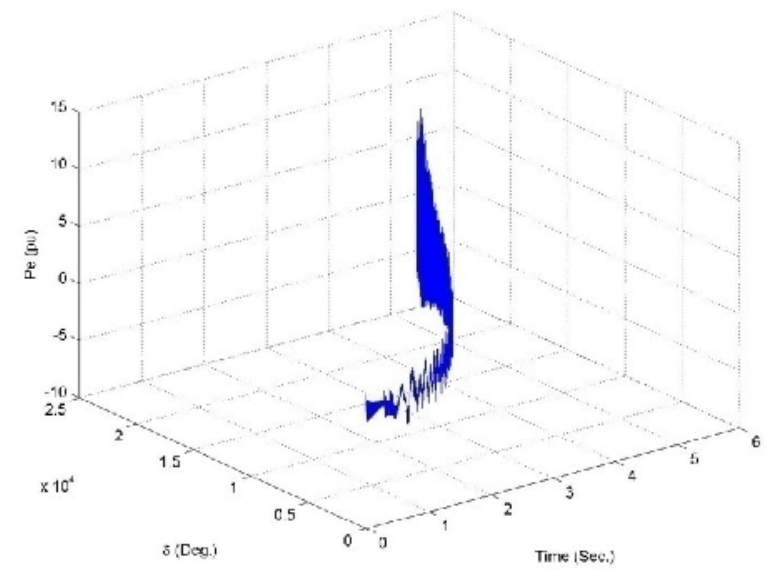

Figure (14): Machine No.2 P-ô-t curve for 400ms 3-phase fault

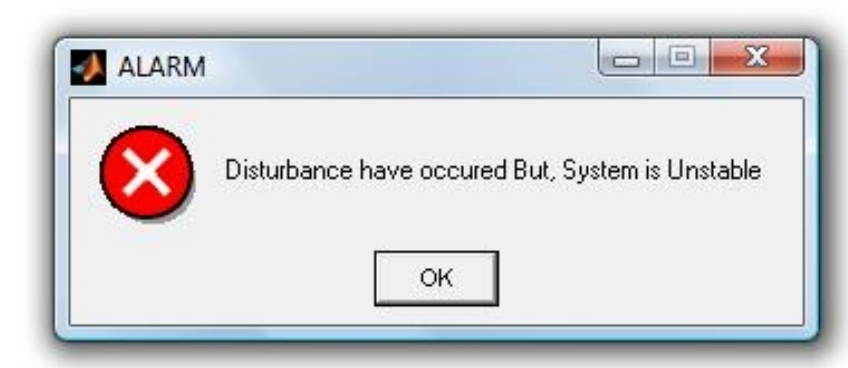

Figure (15): Alarm message for unstable case

\section{Conclusions:}

Stability assessment of multi-machine networks can be determined in real-time via direct algorithm without any estimation via the phasor measurements of SPMUs installed in the network. No need to install PMU units at each bus in the netowrok because, this will make more error in synchronizing all measured phasors through out the network buses/zones and also for economic point of view. So, in order to reduce such errors and cost, the PAs [1] can be employed to reduce number of PMU units for the system and any phasor at any load bus can be calculated directly via direct formula derived in [1] without any iterative procedure. From this point of view a hybrid algorithm for multi-machine networks for stability assessment have the advantages of SPUMs and PAs that will produce more reliability for stability assessment in real-time for the multi-machine network. 


\section{References:}

[1] M. A. Ali and W. M. Mansour: "A Proposed Approach for Online Transient Stability of Multimachine Power Systems Using Parallel Microprocessors", ICEENG 2008 proceedings , EE149, pp:901:910.

[2] Venkatasubramanian, V.; Kavasseri, G.; "Direct computation of Generator internal dynamic states from terminal measurements", IEEE Proceedings of the $37^{\text {th }}$ Hawaii International Conference on System Sciences, 2004.

[3] Vidalinc, A., "On-Line Transient Stability Analysis of a Multi-Machine Power Systems" Virginia Polytechnic Institute and State University, July 1997.

[4] Del Angel, A., "Artificial Neural Networks to estimate rotor angles and speeds from phasor measurements", 2003.

[5] Mohamed A. Ali, Wael R. Anis, Wagdy M. Mansour, Fahmy M. Bendary "ANFIS Based Synchro-Phasors Measurements for Real-Time Estimation of Critical Clearing Time", Proceedings of the 14th International Middle East Power Systems Conference (MEPCON'10), Cairo University, Egypt, December 19-21, 2010, Paper ID 193, PP 422:427.

[6] A. G. Phadke, "Synchronized Phasor Measurements in Power Systems", IEEE Computer Applications in Power, volume.6, N.02, pp.10-15, 1993

[7] A.G. Phadke et al., "Synchronized Sampling and Phasor Measurements for Relaying and Control", IEEE PES Winter Meeting, Columbus, Ohio, Feb.1993(93 WM 039-8-PWRD).

[8] Yeo jun yoon, "Study Of The Utilization And Benefits Of Phasor Measurement Units For Large Scale Power System State Estimation", M.Sc. Texas A\&M University, December 2005.

[9] Ann Helen Berkestedt," Phasor Measurement Based Out-Of-Step Detection" M.Sc., chalmers university of technology Göteborg, sweden, 2007. 
[10] Dongchen Hu and Vaithianathan "Mani" Venkatasubramanian, "New WideArea Algorithms For Detecting Angle Instability Using Synchrophasors", Proceedings of the Western Protective Relay Conference, Spokane, WA, 2006.

[11] Reza Ebrahimpour and Easa Kazemi Abharian, "An Improved Method in Transient Stability Assessment of a Power System Using Committee Neural Networks", IJCSNS International Journal of Computer Science and Network Security, VOL.9 No.1, January 2009. 